\title{
Immunogenicity and Efficacy Evaluation of Vero Cell-Adapted Infectious Bursal Disease Virus LC-75 Vaccine Strain in Ethiopia
}

\section{Wakjira Kebebe}

National Veterinary Institute

Molalegne Bitew

Ethiopian Biotechnology Institute

Fufa Dawo

College of Veterinary Medicine and Agriculture

\section{Bedaso Mammo}

College of Veterinary Medicine and Agriculture

\section{Hawa Mohammed}

National Veterinary Institute

\section{Martha Yami}

National Veterinary Institute

\section{Belayneh Getachew}

National Veterinary Institute

Takele Abayneh

National Veterinary Institute

Esayas Gelaye ( $\square$ esayasgelaye@gmail.com )

National Veterinary Institute https://orcid.org/0000-0002-7329-8632

\section{Research article}

Keywords: Antibody, chicks, IBD vaccine, immunogenicity, protection, Vero cell

Posted Date: March 16th, 2021

DOI: https://doi.org/10.21203/rs.3.rs-310833/v1

License: (c) (i) This work is licensed under a Creative Commons Attribution 4.0 International License. Read Full License 


\section{Abstract}

Background: Infectious bursal disease virus (IBDV) is an avian viral pathogen that causes infectious bursal disease (IBD) of chickens. The disease is endemic in Ethiopia since 2002 and vaccination is the major means of disease prevention and control. IBD vaccine is produced in Ethiopia using primary chicken embryo fibroblast (CEF) cell; which is time-consuming, laborious, and uneconomical. The present study was carried out to develop cell-based IBDV LC-75 vaccine using Vero cells, and to evaluate the immunogenicity and protection level.

Results: Identity of the vaccine seed was confirmed using gene-specific primers using reverse transcription polymerase chain reaction. Confluent monolayer of Vero cells was infected with vaccine virus and serial passage continued till passage ten. Characteristic virus induced cytopathic effect was observed starting from passage 2 on the third day post-infection. The infectious titer of adapted virus showed a linear increment along the passage level. Virus induced specific antibody was determined using indirect ELISA after vaccination of 14 days old chicks through ocular route. Accordingly, the antibody titer measured from Vero cells vaccinated chicks revealed similar level with the currently available CEF cellbased vaccine. Chicks vaccinated with Vero cell adapted virus showed complete protection against very virulent IBDV, while unvaccinated group had $60 \%$ morbidity and $25 \%$ mortality.

Conclusions: The IBDV vaccine strain well adapted on Vero cells and found to be immunogenic induces antibodies development and successfully protects chicks against challenging with the circulating field IBDV isolate. Hence, it is recommended to produce IBD vaccine using Vero cell culture with enough quantity to conquer the limitations using CEF cells and thus to vaccinate chicks to protect against IBDV infection.

\section{Background}

Infectious bursal disease (IBD also known as Gumboro) is an immunosuppressive disease of chicken and is the second priority chicken disease in Ethiopia [1] that needs to be controlled primarily through vaccination. The etiological agent is IBD virus (IBDV) belongs to the family Birnaviridae which is a nonenveloped, icosahedral in shape with double-stranded and bi-segmented ribonucleic acid (RNA) genome [2]. The majority of chicken production in Ethiopia is under small scale backyard management system and they serve as source of egg and meat consumptions and for generating cash income. In general, Ethiopia has around 60.5 million poultry [3]. Losses due to chicken mortality occur in different age groups due to presence of different poultry diseases including IBD. Among the causes of the poultry disease in Ethiopia, IBD is one of the diseases which is challenging chicken production and product quality. IBD was first reported in Ethiopia in 2002 at privately owned commercial poultry farm in which $45-50 \%$ mortality rate was reported [4]. Subsequently, IBD has become a second priority problem next to Newcastle disease in both commercial and backyard poultry production systems in Ethiopia despite regular vaccination practices (in commercial farms) using IBDV LC-75 vaccine and improved biosecurity measures [5]. Since then, the circulation of very virulent $[6,7]$ and/or classical virulent IBD viruses [6] were reported from 
different parts of Ethiopia. Vaccination is the cheapest, most practical and economical method of disease control globally. Most control strategies designed in the country do not take into consideration the local chickens which contribute to $99 \%$ of the chicken population. Despite that improved chicken genotypes are being distributed to smallholder farmers in the country by different organizations as a means to improve livelihood of the farmers and these development activities failed because of presence of priority endemic poultry diseases like IBD and Newcastle disease. Previously, Tadelle and Ogle [8] reported that chicken vaccination against prevailing diseases in Ethiopia did not take into account local chicken population found under smallholder farmers' management conditions. Starting from 2004, highly pathogenic IBDV strains emerged via mutation and genetic re-assortment [9]. IBD is a contagious and economically important poultry disease in Ethiopia [10]. Unless the chickens get vaccine during their early life (2 to 6 weeks of age), it leads to considerable economic loss. Therefore, vaccination is considered as an important means of protecting birds during their first weeks of life [11]. One of the strategies to prevent and control IBD is to hyper-immunize breeders with vaccines [12]. Although passive immunity promotes good protection of chickens during the first weeks of life, permanent protection against IBD requires the administration of live vaccines [13]. The live IBD vaccines so far developed and in use are categorized as "mild", "intermediate" and "hot" according to their degree of virulence [14]. Mild vaccines are safe for specific pathogen-free (SPF) chickens but are not very effective in the presence of high levels of maternal antibodies or against very virulent strains of IBDV. Hence, the intermediate and hot vaccines are much more effective but may induce moderate to severe lesions in the Bursa of Fabricius [14]. Currently, Ethiopia is producing live intermediate plus IBDV vaccine using LC-75 strain using chicken embryo fibroblast cell (CEF) [7] at the National Veterinary Institute (NVI). Production of IBD vaccine based on CEF cells needs high human labor for preparation of primary cells, costly since it needs use of specific pathogen-free eggs and is time-consuming with a minimum production capacity. Different cell lines such as Vero cells are also suitable for the growth of IBDV so that for vaccine production it is easily manageable and reproducible with a minimum cost but needs proper adaptation of the vaccine strain to the Vero cells. Therefore, in this paper we reported adaptation of IBDV vaccine strain (intermediate plus LC-75) on Vero cell, and evaluation of the immunogenicity and efficacy of Vero cell adapted vaccine strain in target host.

\section{Results}

\section{Adaptation of IBDV LC-75 on Vero Cells}

The result of the present study showed that the LC-75 strain of IBDV vaccine strain successfully adapted in Vero cell culture starting from passage two to ten. At the first passage, the infected cells remained intact on the surface of tissue culture flask and did not show any CPEs formation. During second passage, minor CPEs were observed starting from day four post-inoculation. However; starting from passage three up to passage ten, visible CPEs happened at day three post-infection by observing typical aggregation, rounding and clumping of large number of cells and detachment of infected cells with few cells floating in media as visualized by inverted microscope (Fig. 1). 


\section{Titration of IBDV}

The infectivity of adapted IBDV LC-75 to Vero cells was determined by calculating $50 \%$ endpoint as described by Spearman Karber method [16]. The total infectious virus $\log _{10} T C{ }^{2} D_{50} / \mathrm{ml}$ titer of Vero cell adapted passage $2,3,5,7,9$ and 10 were 5.4, 5.60, 5.9,6 and 6.2, respectively (Fig. 2). The best-fit equation for the log titer increment was $Y=5.0695+0.1104 x$ (" $x$ " stands for passage number).

\section{Molecular detection and sequencing}

The amplified PCR products were visualized on agarose gel electrophoresis that resulted in the generation of 645 bp expected size amplicon of the VP2 gene (Fig. 3). PCR amplicons obtained from virus-infected Vero cell homogenates were confirmed as IBDV (Fig. 3). The VP2 gene nucleotide sequences of the present LC75 vaccine strain viruses isolated from the different culture passages were deposited in the GenBank with accession numbers of IBDV/LC-75/passage 1 (MK798159), IBDV/LC-75/passage 5 (MK798160) and IBDV/LC-75/passage 10 (MK798161).

\section{Immunogenicity of the developed vaccine}

The indirect ELISA test result showed that all chicks contained fewer amount of maternally derived antibody that is within the negative range of the S/P ratio. Seven days post-inoculation of the antigen, the mean S/P ratio for Group 1 inoculated from passage 5 was 0.046 (antibody titer 141.86), for Group 2 inoculated from passage 10 was 0.068 (antibody titer 207.27) and for Group 3 inoculated with CEF cellbased vaccine was 0.094 (antibody titer 283.75). At day 14 post-inoculation S/P ratio was 1.28 (antibody titer 3572.68) for passage 5, 1.53 (antibody titer 4247.67) for passage 10 and 1.76 (antibody titer 4865.72) for CEF based vaccine (Gum 01/18). At day 21 post infections the S/P ratio or antibody titer seems equal with that of day 14 post-inoculation (Fig. 4). The chickens were boosted at day fourteen post-inoculation and, after 7 - 14 day of boosting, the S/P ratio was strongly increased from 1.53 (antibody titer 4247.67) to 2.15 (antibody titer 6307.77) (Fig. 4).

\section{Immunogenicity and efficacy evaluation}

The comparison of IBD virus antibodies produced against Vero cell adapted virus from passages 5 and 10 with that of CEF cell based NVI vaccine (Batch Gum 01/18) showed the absence of significant difference between the two IBD vaccines used.

Chick groups vaccinated with Vero cell adapted LC-75 IBDV strain from passages 5 and 10 and from CEF cell based vaccine (Batch Gum 01/18) was found to be safe as no clinical signs and death were observed as compared to the unvaccinated control group (Fig. 5). Starting from day 4 post-inoculations of challenge virus, $60 \%$ of chicks from control (unvaccinated) group showed clinical signs such as ruffled 
feather, inappetence, difficult movement, yellowish diarrhea and dehydration, while $25 \%$ of the unvaccinated chickens died starting from day 6 post-challenge.

\section{Discussion}

The CEF cell-based vaccine production needs SPF chicken eggs, nevertheless obtaining of SPF eggs and processing of the embryo needs hard currency to import the SPF eggs and also incurs additional labor cost as its processing is labor-intensive and cannot be easily scaled up for large scale vaccine production. The use of Vero cell line for the IBDV vaccine production could be the best alternative.

In the present study, IBDV LC-75 vaccine strain was successfully adapted in Vero cells and the titer was compared with the IBD vaccine produced using chicken embryo fibroblast cells using the same vaccine strain. The Vero cell adapted IBDV LC-75 vaccine strain at different passages were proved to be immunogenic and protected chickens against challenge with vvIBDV field strain (MB/263/17). Hence, the Vero cell based IBDV vaccine is recommended for ultimate vaccine production and use in Ethiopia. Previously, it was suggested that the use of Vero cells in growing avian viruses could become an economical, less laborious, and continuous and efficient tool with an advantage of measuring virus effects outside the host animal [21] as compared to the laborious preparation of primary CEF cell. We have tested that confluent monolayer of Vero cells, following 36 hours of sub-culturing in growth medium, infected with IBDV LC-75 remained fully intact in passage 1 (P1) up to six days post-infection. When the first passage virus was blindly harvested and passaged (second passage or P2), some changes in Vero cell monolayer began to develop on fourth day of incubation. Monolayer showed rounding of infected cells but complete CPEs of IBDV on Vero cells were not found in this passage too. CPE was observed starting from day three post-infection after the virus became adapted to the cell. This indicated that the virus had adjusted itself to Vero cell culture environment and started replication with good and observable CPEs. Hussain and Rasool [15] also reported that the passage level and the time at which the CPE observed and completed was similar to the present study. On the other hand, Isabela et al. [22] reported that detection of IBD virus titer inoculated on Vero cell was not observed and this could be related to the strain of the IBD virus or passage level used. The current result also indicated presence of difference in time of CPEs observation with that of Silva et al. [21] that reported IBDV CPEs in Vero cells at 18 hours post-infection. The titer of Vero cell adapted IBDV LC-75 strain increased with passage number starting from passage 3 indicating that the vaccine strain is well adapted to Vero cell environment and the virus replicates successfully to high titer as shown in Figure 2. The figure shows that as the passage number increases, the titer of the virus increases linearly. For example, in passage 3 , the vaccine strain had a titer of $\log _{10} 5.40 \mathrm{TCID} / \mathrm{ml}$. According to Code of American Federal Regulation [23], IBD vaccine strain titer must not be less than $\log _{10}{ }^{3.40} \mathrm{TCID}_{50} /$ dose and the current titer $\left(\log _{10} 5.40\right.$ $\mathrm{TCID} / \mathrm{ml}$ ) is higher than recommended by Code of American Federal Regulation [23] for protecting chickens against the disease. This suggests that the $3^{\text {rd }}$ passage could be used as a vaccine to protect the chicken against vvIBDV. Previously, Hussain and Rasool [15] also reported similar findings in growth pattern of vvIBDV in Vero cells at passage 3 after 72 hours of infection. To confirm identity of the Vero- 
cell adapted IBDV LC-75 vaccine strain, RT-PCR test conducted amplifying the VP2 region. As expected, we amplified and sequenced the expected $645 \mathrm{bp}$ band of the VP2 gene fragment. Sequencing of the VP2 gene was recommended for checking absence of nucleotide and/or amino acid change since VP2 gene is responsible for the antigenicity [24], antigenic variation [25], and pathogenicity of the IBD virus

[1]. Immune response status following vaccination was assessed using iELISA at 7 days post-inoculation, and all groups of chickens had contained antibody titer less than positive range $(>0.3)$ suggesting that the vaccine might not provide sufficient protection within a week. Starting from day 7 up to day 14 postinoculation, all groups of chickens inoculated with both Vero cells adapted virus and NVI-Gum 01/18 vaccine had increased antibody titer from 213.18 to 4220.74 or S/P (0.07 to 1.52$)$. The mean antibody produced at day 14 post inoculations were closely similar with day 21 post-inoculation (7 days postboost, Figure 4) suggesting as the maximum immune response was achieved but the exact day on which maximum immune response was achieved need to be determined by sampling the animals between days 14 and 21 and after 21 day. A similar idea was reported by Ahmad et al. [26] that the antibody titer at 14 days of post-infection resulted in a gradual increase of antibody values in all inoculated groups. This result also agreed with the report of Rautenschlein et al. [27] about immunity reaction to intermediate plus or "hot" vaccine of IBDV. As reported by Rautenschlein et al. [27] the intermediate plus vaccine-induced antibody levels already at 14 days post-vaccination. The mean S/P ratio was highly increased starting from day 21 post-inoculation. Due to that, all groups of chickens were boosted at day 14 post-inoculation, antibody production was enhanced and mean S/P ratio or the antibody titer increased. In all types of infections, there was no significant difference in antibody production. Therefore, Vero cell adapted IBDV vaccine strain IBDV is equally immunogenic at passages 5 and 10 with that of chicken fibroblast cellbased prepared vaccine. Upon comparative evaluation of the efficacy of the Vero cell adapted and CEF cell based vaccine against challenge with local field strain of vVIBDV, chickens vaccinated by the two celltype based vaccines were fully protected with no mortality and morbidity. The challenged control chickens (unvaccinated groups) responded by high morbidity and mortality rate starting from $3^{\text {rd }}$ day post-challenge. There were clinical manifestations of anorexia, ruffling of feathers and death on day 6 post-infection but no any clinical sign and death occurred in pre-vaccinated chickens. Therefore, Vero cell adapted virus is efficacious to protect the vvIBDV circulating in Ethiopia similar to that of CFC based prepared vaccine as described previously by OIE [13].

\section{Conclusion}

The present study confirmed that Vero cell adapted attenuated IBDV vaccine could be successfully produced similar with that of the CEF cell vaccine. The IBDV vaccine strain LC-75 was adapted well on Vero cells as early as passage 3 with a good virus titer $/ \mathrm{ml}$. The adapted vaccine is equally immunogenic and efficacious with no difference between passages and CEF cells based prepared vaccine. It is more economical to produce IBDV vaccine using Vero cells. Based on the above conclusions, production of IBDV vaccine using Vero cell line is recommended. In the future, a closely related cell type like avian stem cells or cell line developed from chicken could replace Vero cells and CEF cells for better vaccine 
production of avian pathogens as it allows use of host-related cell type for vaccine production that overcomes adaptation problem and also facilitates better vaccine production.

\section{Methods}

\section{Virus and cell culture}

IBD virus intermediate plus LC-75 vaccine strain was used for the Vero cell culture adaptation. A challenge IBD virus, $\mathrm{NVI} / \mathrm{MB} / 263 / 17$, with infectious titre log $10^{5.3} \mathrm{TCID} 50 / \mathrm{ml}$ was used for assessing the protective potential of the vaccine. Vero cell, vaccine strain and challenge field virus isolate were obtained from the virology laboratory, Research and Development Directorate, NVI. Dulbecco's Modified Eagle's Medium (DMEM, HIMeDIA) with $10 \%$ and $2 \%$ sterile fetal calf serum (FCS, Gibco) was used as a growth and maintenance medium for Vero cell culture, respectively. Media and solutions used for the growth of cells were Trypsin versine solution, phosphate buffered saline (PBS) and tryptose phosphate broth (TPB). Culture media were prepared according to the manufacturer's instruction (HIMeDIA).

\section{Adaption of vaccine strain using Vero cells}

Vero cells were grown in $75 \mathrm{~cm}^{2}$ cell culture flask until confluent monolayer of cells was obtained. Confluent Vero cell monolayer was washed three times using prewarmed PBS pH7.4 to remove dead cells and suspended using pre-warmed $0.25 \%$ trypsin/EDTA solution. Cell viability was checked with trypan blue stain and the number of viable cells was counted using cell counter EVE ${ }^{\mathrm{TM}}$ Automatic cell counter (E16041- 016, NanoEnTekInc, Korea). The viable cells were counted and seeded into $75 \mathrm{~cm}^{2}$ tissue culture flask containing pre-warmed DMEM (Sigma-Aldrich) with sterile $10 \%$ fetal calf serum (FCS, Gibco) at a seeding density of $2.1 \times 10^{6}$ cells. The cells were incubated at $37^{\circ} \mathrm{C}$ with $5 \% \mathrm{CO}_{2}$. The cells were observed under inverted microscope for the formation of confluent monolayer [15].

\section{Infectious Bursal Disease virus inoculation into Vero cell}

Confluent monolayer of Vero cells at 36 hours after sub-culturing was washed three times using prewarmed sterile PBS and used for virus infection using adsorption method. The cells were infected by adding $0.5 \mathrm{ml}$ of IBDV LC-75 vaccine strain and incubated at $37^{\circ} \mathrm{C}$ for 1 hour with intermittent tilting of the flask to allow adsorption. After one-hour incubation, $10 \mathrm{ml}$ DMEM with $2 \%$ FCS was added into an infected flask and placed into $37^{\circ} \mathrm{C}$ incubator with $5 \% \mathrm{CO}_{2}$. One flask of fresh cells with confluent monolayer was kept as control under similar condition. The infected cells were observed daily for the development of virus induced cytopathic effects (CPE) for six days. At six days of post-inoculation the infected cells with the virus were harvested, labelled and stored at $-80^{\circ} \mathrm{C}$ for $24 \mathrm{hrs}$. The harvested virus was freeze-thawed alternatively three times at $-80^{\circ} \mathrm{C} /+30^{\circ} \mathrm{C}$ and inoculated to fresh monolayer of Vero 
cells. This process was repeatedly conducted up to passage 10 (P10). At each passage, the harvested flasks were labeled and stored at $-80^{\circ} \mathrm{C}$ until subsequent experiments.

\section{Titration of infectious bursal disease virus}

The viral suspension kept at $-80^{\circ} \mathrm{C}$ was diluted 10 -fold in sterile tubes $\left(10^{-1}\right.$ to $\left.10^{-10}\right)$ of passages $2,3,5,7$, 9 and 10 . Then $100 \mu \mathrm{l}$ viral dilutions were dispensed into 96 well micro plates containing $100 \mu l$ Vero cells per well with ten replicates for each dilution. Column 11 was left empty and column 12 was inoculated only with cells to serve as negative control. Finally, the plate was sealed by micro plate sealer and incubated at $37^{\circ} \mathrm{C}$ in $5 \% \mathrm{CO}_{2}$. The inoculated plates were monitored under inverted microscope daily starting from 72 hours post-inoculation for eight days. The titre for each virus passage was determined according to Spearman Karber method [16].

\section{Molecular characterization of IBD virus adapted in Vero cell}

The identity of the IBD vaccine strain virus adapted in Vero cell was checked by amplification of the viral hypervariable core protein (VP2) gene of the IBD virus using gene-specific primers by reverse transcription polymerase chain reaction (RT-PCR) [17]. The VP2 gene amplification was done on vaccine working seed and from passages $1,3,5,7,9$ and 10 .

\section{RNA extraction, CDNA synthesis and RT-PCR}

Virus RNA extracted from the harvested virus using the RNeasy® Mini Kit (Qiagen) following the manufacturer's instruction. The extracted RNA was subjected to two steps RT-PCR. A 10 $\mu$ l reaction mix was prepared from $3 \mu \mathrm{l}$ RNase free water, $1 \mu \mathrm{l}$ Oligo dT, and $1 \mu \mathrm{l}$ of $10 \mathrm{Mm}$ dNTP mix. Then, $5 \mu$ template RNA was added and incubated at $65^{\circ} \mathrm{C}$ for 5 minutes and placed at $4^{\circ} \mathrm{C}$. A $10 \mu$ l volume for CDNA synthesis mix was prepared from $1 \mu \mathrm{l}$ DEPC treated water, $2 \mu$ l of $1 \mathrm{X} \mathrm{RT}$ buffer, $4 \mu \mathrm{l}$ of $25 \mathrm{mM} \mathrm{MgCl}_{2}, 2 \mu \mathrm{l}$ of $0.1 \mathrm{MDTT}$, and $1 \mu$ l superscript III-RT enzyme and incubated at $55^{\circ} \mathrm{C}$ for 50 minutes. The reactions were terminated at $85^{\circ} \mathrm{C}$ for 5 minutes and chilled on ice and then collected by brief centrifugation to which $1 \mu \mathrm{l}$ RNase was added per sample and incubated for 20 minutes at $37^{\circ} \mathrm{C}$. Finally, the obtained cDNA was immediately used for PCR. For running PCR, a total of $20 \mu \mathrm{l}$ master mix was prepared by using $3 \mu \mathrm{l}$ of RNase free water, $2 \mu \mathrm{l}$ of forward primer, $2 \mu$ l of reverse primer, $10 \mu$ l of IQ super mix (Bio-Rad) and $3 \mu \mathrm{l}$ of template cDNA. The amplification forward and reverse primers used for the RT-PCR reaction to amplify the segment A, VP2 gene of the virus were used from the previously described method [18]. The two primers are expected to amplify 645 base pairs of the VP2 gene. Master mix was prepared and amplified using touchdown PCR (thermal cycler 2720, applied Bio-system). The PCR cycles involved initial denaturation at $95^{\circ} \mathrm{C}$ for 5 minutes, followed by 15 cycles of denaturation at $95^{\circ} \mathrm{C}$ for $30 \mathrm{sec}$, annealing at $60^{\circ} \mathrm{C}$ for $30 \mathrm{sec}$, and elongation at $72^{\circ} \mathrm{C}$ for $30 \mathrm{sec}$. The 15 cycles of initial PCR followed by 20 cycles of denaturation at $95^{\circ} \mathrm{C}$ for $30 \mathrm{sec}$, annealing at $56^{\circ} \mathrm{C}$ for $30 \mathrm{sec}$, extension at $72^{\circ} \mathrm{C}$ for $30 \mathrm{sec}$ and final 
extension at $72^{\circ} \mathrm{C}$ for 7 minutes for 1 cycle. The amplified PCR products were stained with GelRed ${ }^{\circledR}$ (Biotium) and visualized using 1.5\% agarose gel electrophoresis in 1X TAE buffer. A 100 bp DNA ladder (Fermentas) was used and IBD virus positive samples yielded a PCR product of $645 \mathrm{bp}$ band size.

\section{Immunogenicity and efficacy tests}

A total of eighty fourteen days old Koko breed specific pathogen free chicks of both sex were used for vaccine evaluation study. Chicks obtained from the Ethiopian Institute of Agricultural Research, Bishoftu and screened for presence of maternal antibody against IBD virus using indirect ELISA test (IDvet, France) before commencing the animal experiment. All maternal antibody free chicks aged fourteen-day were grouped randomly into four groups (group 1-4); the sample size (number of chicks) per group were 20 chicks (total 80 chicks) according to OIE recommendation [13] to be included in one experimental group. The chicks were managed under the same animal facilities of separated room for each treatment group with similar management to avoid any confounding factors among the different groups. Group 1 and 2 were inoculated with Vero cell adapted IBDV passage 5 and 10, respectively. Group 3 chicks were inoculated with Gumboro vaccine produced based on chicken embryo fibroblast cell, Batch number NVIGum $01 / 18$, for comparison of immunogenicity test of Vero cell adapted IBDV, and group 4 served as negative control. At 18 days of age chicks were inoculated using ocular route with $1^{\wedge} 10^{5.4} \mathrm{TCID}_{50}$ antigen from passage 5, 10 and from CEF cell based IBDV vaccine batch (Gum 01/18) which was the product of the NVI, Bishoftu, Ethiopia. The chicks were boosted at day 14 post-inoculation. Blood samples were collected from all treatment groups on day $7,14,21$, and 28 post-inoculation and subjected to indirect ELISA for antibody detection and titration. Efficacy test was conducted by inoculating challenge virus, vvIBD-VMB/263/17 with titre $\log 10^{5.3} \mathrm{TCID} 50 / \mathrm{ml}$ dose $(0.2 \mathrm{ml} / \mathrm{chick})$ to vaccinated and non-vaccinated control chicken groups on 21 days post-vaccination by inoculating through eye drop route [19]. The challenged birds were observed for 10 days for morbidity and mortality and the results were recorded as per OIE recommendation [13]. The chicks were identified using unique identification number attached on the wing and grouped and follow up till data analysis blindly.

\section{Indirect ELISA}

Indirect ELISA test was done at the NVI following the manufacturers' instruction (IDvet, France). Optical density (OD) of the test result was read by using microtiter plate reader at $450 \mathrm{~nm}$ absorbance. The percentage positivity for test samples in relation to the negative and the positive controls was calculated as per the formula given by the kit manufacturer. The result was interpreted with reference to the cut-off value recommended by the manufacturer as the $\mathrm{OD}_{\mathrm{PC}}$ (positive control) should be $>0.25$, and $\mathrm{OD}_{\mathrm{PC}} / \mathrm{OD}_{\mathrm{NC}}$ should be $>3.0$; formula indicated at the data management section.

\section{Animals management}


All experimental chicks handled according to the NVI animal handling and research ethics guideline. Feed and water provided ad libitum. After the end of the experiment, the chicks were euthanized humanly using manual cervical dislocation involved stretching and separating the cervical vertebrae by hand and properly incinerated using the incinerator located inside the institute compound considering all the biosafety and biosecurity measures. Ethical clearance obtained from the animal research ethical review committee, certificate Ref. No: AAU/CVMA/VM/ERC/28/05/10/2018.

\section{Data management and statistical analysis}

All the collected data were entered into Microsoft Excel spread sheet program and analyzed using STATA version 12 [20]. A one-way analysis of variance (ANOVA) was used to differentiate effect of passage levels on immunogenicity of vaccines in chicks. Statistical significance was based on $p<0.05$. The formula used for calculation of sample antibody level was taken from the kit manufacturer as described below.

$S P$ value $=O D_{\text {sample }}-O D_{N C} / O D_{P C}-O D_{N C}$

Where; SP: sample to positive ratio, OD: optical density, NC: negative control, PC: positive control.

\section{Abbreviations}

CEF, chicken embryo fibroblast; CPE, cytopathic effects; DMEM, dulbecco's modified eagle's medium; iELISA, indirect enzyme linked immunosorbent assay; FCS, fetal calf serum; IBDV, infectious bursal disease virus; NVI, national veterinary institute, OD, optical density; OIE, world organization for animal health; PBS, phosphate buffered saline; SPF, specific pathogen-free; TCID, tissue culture infectivity dose; TPB, tryptose phosphate broth; VP2, viral hypervariable core protein; vvIBDV, very virulent IBDV.

\section{Declarations}

\section{Ethics approval and consent to participate}

Ethical clearance for this study was obtained from animal research ethics and review committee, College of Veterinary Medicine and Agriculture, Addis Ababa University, Bishoftu, Ethiopia (AAU/CVMA/VM/ERC/28/05/10/2018).

\section{Consent for publication}

Not applicable.

\section{Availability of data and material}


The sequence data are available at the National Center for Biotechnology Information (NCBI) (Genbank accession numbers: MK798159-61).

\section{Competing interests}

The authors declare that there is no conflict of interest.

\section{Funding}

The research was funded by the National Veterinary Institute (NVI) by providing the laboratory facilities, reagents, consumables and animal experiment rooms. The Ministry of Innovation and Technology (MInT) of Ethiopia financially supported the research activities through the project "Development of a novel immuno prophylaxis for Infectious Bursal Disease and Fowl cholera from local isolates". The funding body had no role in the design of the study, sample collection, statistical analysis and interpretation and writing of the manuscript.

\section{Authors' contributions}

Conceived and designed the experiments: EG, MB, WK, FD, TA. Performed the experiments: WK, EG, HM. Analyzed the data: WK, EG, MB, FD, BM, BG, TA. Contributed reagents/materials: WK, EG, MB, BG, TA, MY. Wrote the paper: WK, EG, MB, FD, BM, TA. Supervised the study: EG, FD. Edited the final manuscript: EG, $\mathrm{MB}, \mathrm{FD}, \mathrm{BM}, \mathrm{BG}, \mathrm{TA}, \mathrm{MY}$. All authors have read and agreed to the published version of the manuscript.

\section{Acknowledgements}

We would like to thank the NVI for giving the chance for the first author to pursue his postgraduate study and allow him to conduct the research in the institute facilities. Mrs Wubet W/Medhin, Mr Abenet Legesse and Mr Alebachew Belay are appreciated for the technical assistance during laboratory assays. The Animal Production and Health sub-program of the IAEA, Vienna, Austria is highly acknowledged for supporting the sequencing service through Member States supporting program.

\section{Author details}

${ }^{1}$ National Veterinary Institute, PO Box: 19, Bishoftu, Ethiopia. ${ }^{2}$ Ethiopian Biotechnology Institute, PO Box: 32853, Addis Ababa, Ethiopia. ${ }^{3}$ College of Veterinary Medicine and Agriculture, Addis Ababa University, PO Box: 34, Bishoftu, Ethiopia

\section{References}

1. Brandt M, Yao K, Liu M, Heckert RA, Vikram N, Vakharia VN. Molecular Determinants of Virulence, Cell Tropism, and Pathogenic Phenotype of Infectious Bursal Disease Virus. Virol. 2001;75(24):1197411982. 
2. Delmas B, Attoui H, Ghosh S, Malik YS, Mundt E, Vakharia VN. ICTV report consortium. ICTV virus taxonomy profile: Birnaviridae. Gen. Virol. 2019;100:5-6.

3. Central Statistical Authority (CSA) Agricultural sample survey. Report on livestock and livestock characteristics. Central Statistical Authority, Addis Ababa, Ethiopia, April, 2015/16.

4. Zeleke A, Yami M, Kebede F, Melese N, Senait B, Gelaye E, Sori T, Ayelet G, Berhanu B. Gumboro: An emerging disease threat to poultry Debre Zeit. Ethio. Vet. J. 2002;6:1-7.

5. Zeleke A, Gelaye E, Sori T, Ayelet G, Sirak A, Zekarias B. Investigation of infectious bursal disease outbreak in Debre Zeit. Int. J. Poult. Sci. 2005;7:504-506.

6. Jenbere S, Lynch SE, Kebede F, Christley RM, Gelaye E, Negussie H, Asmare K, Ayelet G. Genetic characterization of infectious bursal disease virus isolates in Ethiopia. Tropica. 2014;130:39-43.

7. Mekuriaw A, Bitew M,Gelaye E, Mamo B, Ayelet G. Infectious bursal disease: Outbreak investigation, molecular characterization, and vaccine immunogenicity trial in Ethiopia. Anim. Hlth. Prod. 2017;49(6):1295-1202.

8. Tadelle D and Ogle B. Village poultry production systems in the central highlands of Ethiopia. Trop. Anim. Hlth. Prod. 2001;33:521-537.

9. Mardassi H, Khabouchi N, Ghram A, Namouchi A, Karboul A. A very virulent genotypes of infectious bursal disease virus predominantly associated with recurrent infectious bursal disease outbreaks in Tunisian vaccinated flocks. Avian. Dis. 2004;48:829-840.

10. Samson T. Infectious bursal disease: an important challenge in transforming the Ethiopian poultry sector. Greener. J. of Agri. Sci. 2018;8(10):277-285.

11. Eterradossi $\mathrm{N}$ and Saif YM. Infectious bursal disease. In Diseases of poultry. 12th ed. Ames: lowa. State University Press. 2008, p.185-08.

12. Camilotti E, Moraes LB, Furian TQ, Borges KA, Moraes HLS, Salle CTP. Infectious bursal disease: Pathogenicity and immunogenicity of vaccines. J. Poultry. Sci. 2016;18(2):303-308.

13. Infectious bursal disease (Gumboro disease); Version adopted by the World Assembly of Delegates of the OIE. 2016.

14. Van den Berg TP, Gonze M, Meulemans G. Acute infectious bursal disease in poultry: Isolation and characterization of a highly virulent strain. Avian Pathol. 1991;20:133-143.

15. Hussain I and Rasool MH. Adaptation of an indigenous very virulent infectious bursal disease virus on Vero cell line. Pakistan. Vet. J. 2005;25(3):103-106.

16. Ramakrishnan M. Determination of 50\% endpoint titer using a simple formula. J. Vi. 2016;5(2):85-86.

17. Jackwood DJ. Recent trends in the molecular diagnosis of infectious bursal disease viruses. HIth Res. Rev. 2004;5:313-316.

18. Office of International des Epizooties. Manual of Diagnostic Tests and Vaccines for Terrestrial Animals. Infectious bursal disease: 2012. chap. 2.3.12: p. 549-565. 
19. El-Bagoury GF, Nada AF, El-Sayed El-Habbaa AS, Abu-Zeid AA. Evaluation of an inactivated infectious bursal disease virus vaccine prepared using a local isolate from Egypt. Vet. Med. J. 2015;28:67-77.

20. Stata Corp. Stata Statistical Software: Release 12 College Station, TX: Stata Corp LP. 2011

21. Ahmed H, Mostafa S, Elrefaie R, Ragab I, Jun S, Masanubu G. Growth of different infectious bursal disease virus strains in cell lines from origin of lymphoid leucosis tumors. Vet. Sci. 2015;3(2):46-50.

22. Isabela CS, Maria JB, Fernandes RMC, Alda MM, Clarice WA. Susceptibility of cell lines to avian viruses. Microbiol.1999;30:373-376.

23. CFR (Code of American Federal Regulation-13CFR) USA. Office of the federal register national archives records service, Animals and animal products. 2012, Ch.1 11.30:113-33.

24. Jackwood DJ and Sommer-Wagner SE. Amino acids contributing to antigenic drift in the infectious bursal disease Birnavirus (IBDV). Virology. 2011;409:33-37.

25. Jackwood DH and Saif YM. Antigenic diversity of infectious bursal disease viruses. Avian. Dis.1987;31:766-770.

26. Ahmad AN, Iftikhar H, Masood A, Fehmeeda B. Comparative study of commercially available infectious bursal disease vaccine with egg attenuated live vaccine. J. Zool. 2014;46(4):959-966.

27. Rautenschlein S, Kraemer C, Vanmarcke J, Montiel UE. Protective efficacy of intermediate and intermediate plus infectious bursal disease virus (IBDV) vaccines against very virulent IBDV in commercial broilers. Avian. Dis. 2005;49:231-237.

\section{Figures}
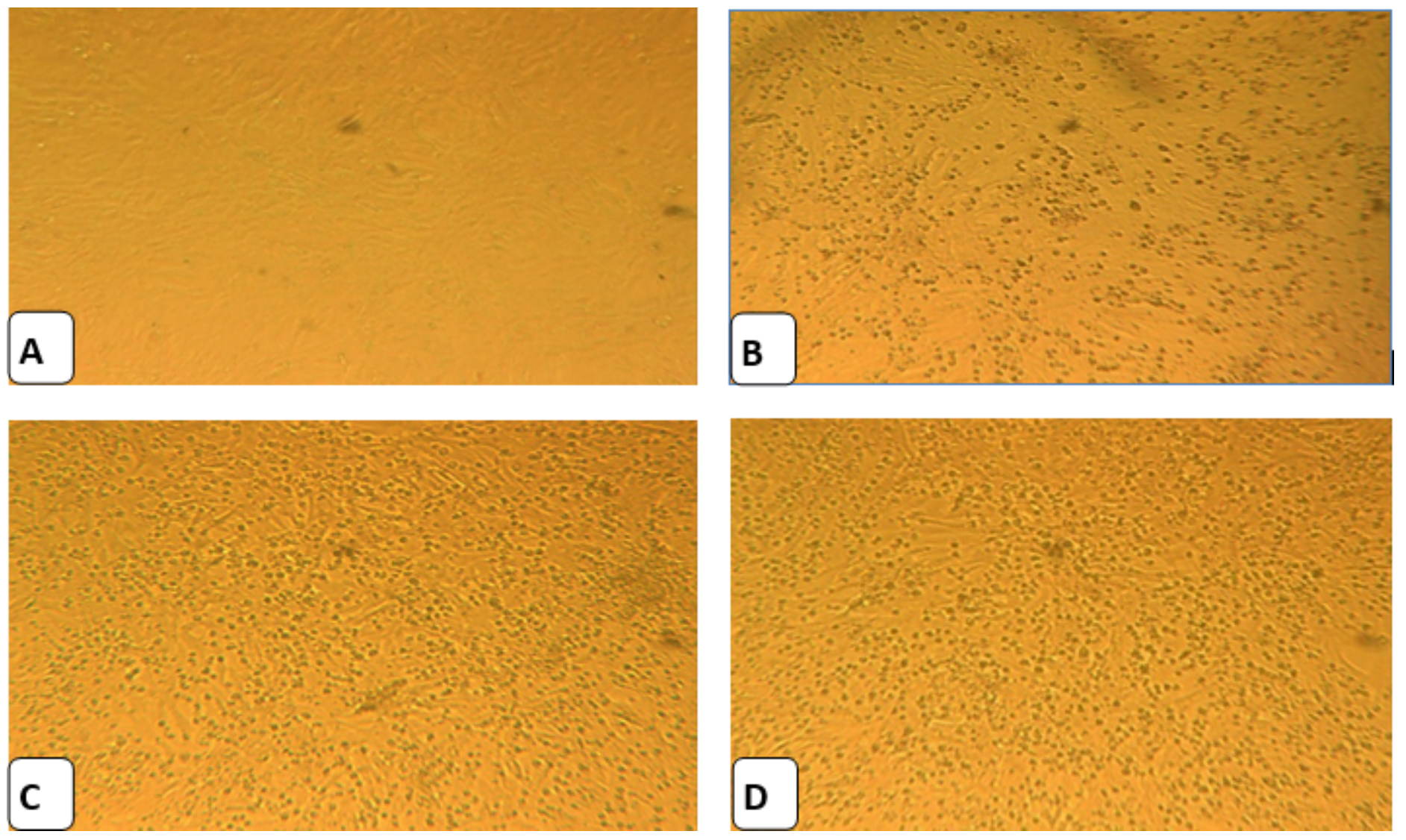
Figure 1

Cytopathic effect (CPE) observed on Vero cell culture infected at different passages of IBDV LC-75 vaccine strain using Inverted microscope (40x). Where; (A) Vero cell control, and observation of CPE were recorded at (B) passage 5, (C) passage 7, and (D) passage 9.

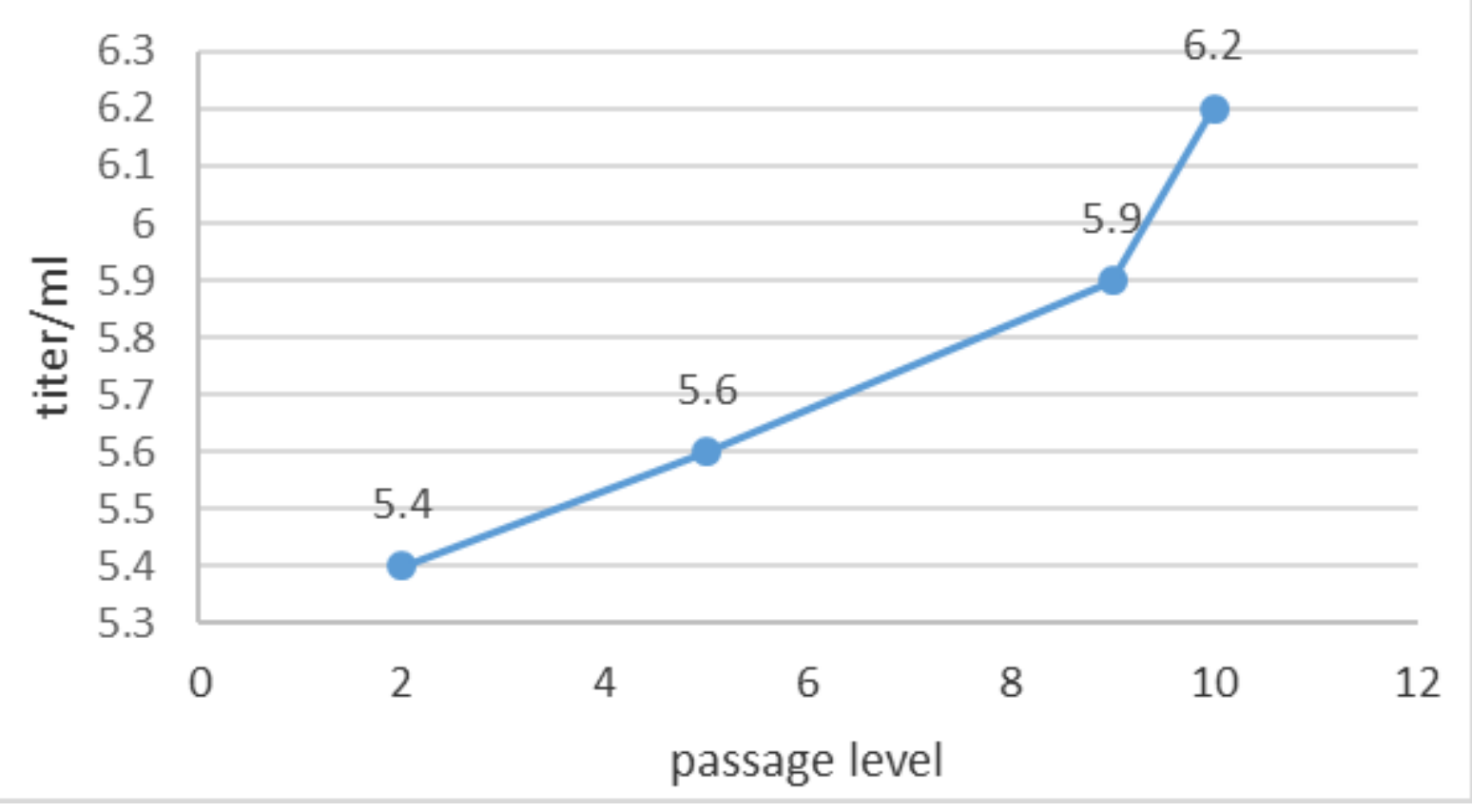

\section{Figure 2}

Vero cell adapted IBD virus titration result at different passage number.

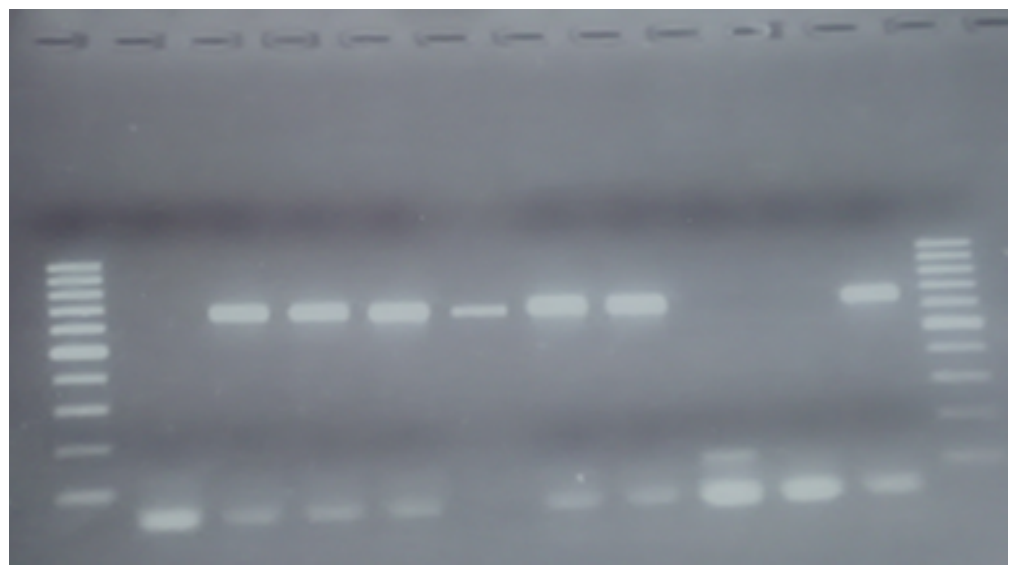

\section{Figure 3}

Agarose gel electrophoresis picture showing the $645 \mathrm{bp}$ fragment of the IBDV VP2 gene. Where; (M) Molecular ladder (100bp, Fermentas), (1) Vero cell control (Negative), (2) Original culture (Positive), (3) Vero cell culture passage 5, (4) Vero cell culture passage 6, (5) Vero cell culture passage 7, (6) Vero cell 
culture passage 8, (7) Vero cell culture passage 9, (8) Extraction control (RNA free water), and (9) Negative control.

2.5

2

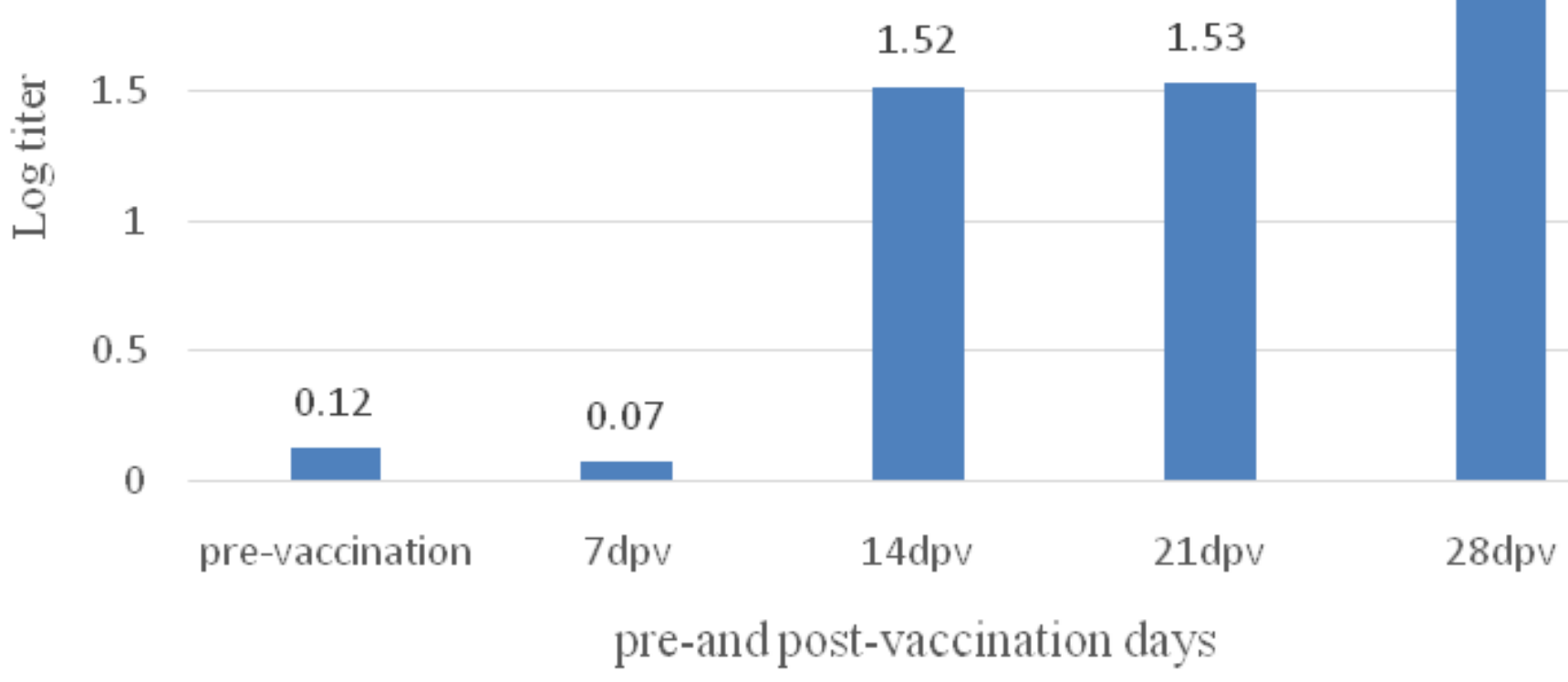

Figure 4

Mean S/P ratio of specific IBDV antibody at pre-and post-vaccination. dpv: days post-vaccination.

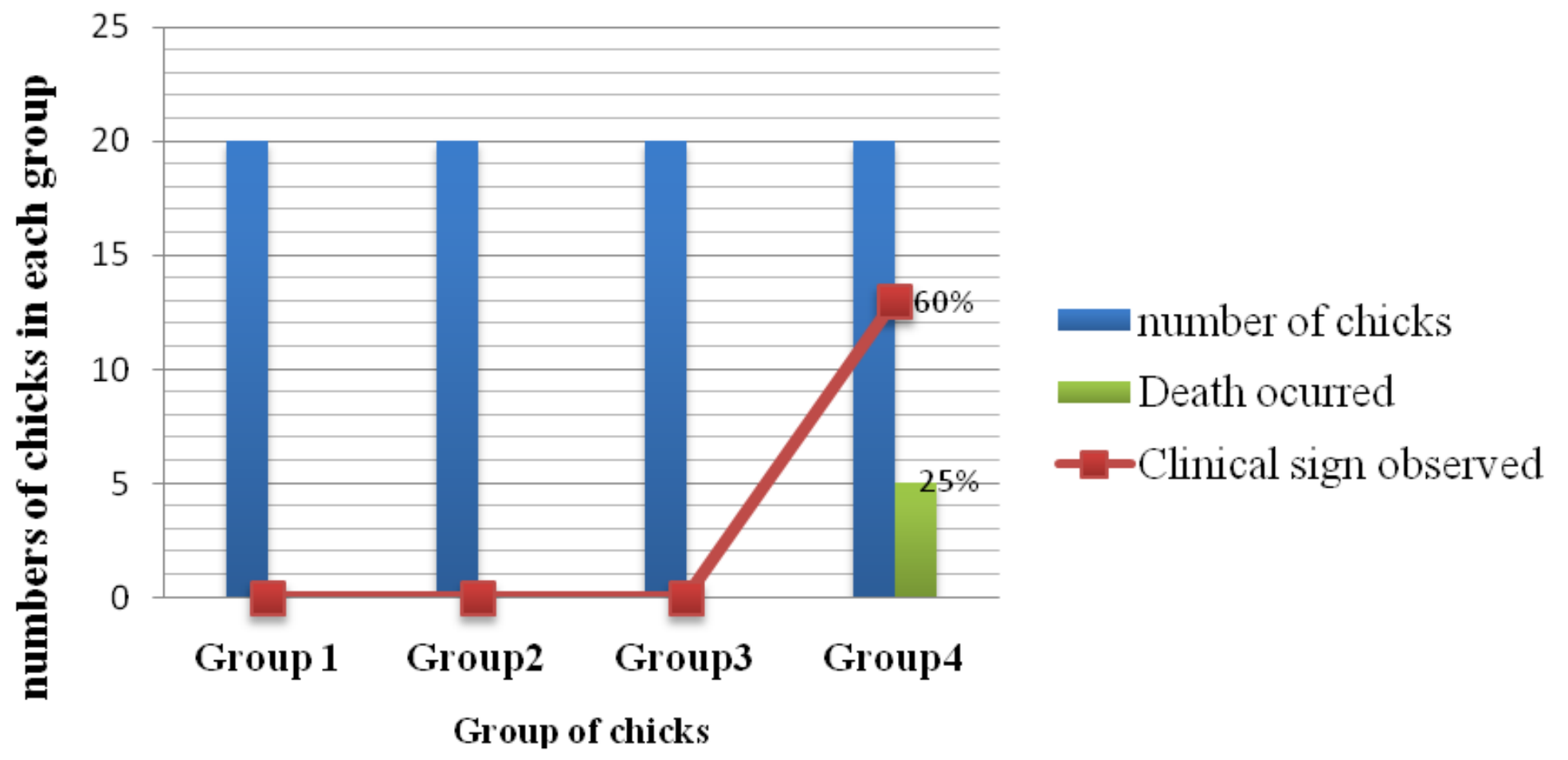

Figure 5 
Percentage of clinical sign and death observed in chicken vaccinated with different vaccine passages and challenged with vvIBDV.

\section{Supplementary Files}

This is a list of supplementary files associated with this preprint. Click to download.

- ARRIVEckecklistBMCVRD2000923R1.pdf 